\title{
The Added Value of Intervision: Its Effect on Management Consultants' Professional Practice
}

\author{
Monique Bellersen, MMBManagement
}

\begin{abstract}
Organisations are paying increasingly more attention to reflection. How do people handle issues cropping up at work? Intervision is a valuable tool. Intervision is a form of expertise development in which professionals call on their peers to help them gain insight into issues they have at work. They unravel a case submitted by one participant by asking questions according to the intervision method of choice.

Management consultants use intervision to explore the way they act and subsequently make the necessary adjustments. The more in-depth the intervision, the higher the added value, as the insights gained touch upon personal values and beliefs.

Prerequisites for depth are safety and confidentiality, as well as questions that impel contemplation. Furthermore, the article discusses preconditions to improve the quality of the intervision.
\end{abstract}




\section{Introduction}

There is growing attention for reflection in both public and private sector organisations. Decades ago, it was not as common to mull over and dwell on things. Today, it is more established to look closely at our own experiences and beliefs. For instance, it is now perfectly normal to have a coach help you scrutinise your own beliefs and suppositions and consider your options. Furthermore, there is a need in organisations for giving and receiving feedback and calling co-workers to account for, or reflect on, their behaviour and performance. Feedback provides insights into potential and developmental needs, not only in terms of expertise, but also in terms of the way a person relates to his profession/position and the way he deals with issues that present themselves. Intervision is a valuable tool to address that need.

Intervision ${ }^{1}$ is mostly known in the Netherlands, Germany, Belgium, France, and Canada where (professional) organisations use intervision with, for example, consultants, education professionals, vocational experts, accountants, interim managers, physicians, lawyers, and notaries, as well as companies, such as IT, construction, energy, and transport companies. For those organisations, intervision is a fixture in the process of lifelong learning. In the Netherlands, Germany and Belgium in particular a variety of intervision methods is used.

\section{What is Intervision?}

A group of five to eight participants unravels a problem submitted by one of the participants, the case provider, by asking questions according to the intervision method of choice. A facilitator guides the discussion. Rather than coming up with solutions, the participants ask their questions to encourage the case provider to think up his own answers. The questions should help the case provider develop new ways of thinking, gain insight into his role and behaviour at work, review his own style or strategy to develop specific competences and new and alternative ways of behaving. Thus, Intervision contributes to enhancing professionalism.

Reflection can take place at three different levels ${ }^{2}$. The levels indicate the degree of depth attained during an intervision session. The higher the level, the more lasting the impact of the intervision on the case provider, since it is at level three where the insights that could drive true change are obtained.

The three levels we identify are:

\section{Case Level: Specific Issue}

The case gets discussed in terms of the issue: what would be more effective? What could I do? What are my alternatives? What worked well and what could have gone

\footnotetext{
${ }^{1}$ Intervision is a form of expertise development in which professionals call on their colleagues, fellow professionals or peers to help them gain insight into the problems they have at work. From: Bellersen, M. and Kohlmann, I., Intervision; dialogue methods in action learning, Vakmedianet, 2016

${ }^{2}$ From: Bellersen, M. and Kohlmann, I., Intervision; dialogue methods in action learning, Vakmedianet, 2016
} 
better? At this level the content of the case is most important. Neither the underlying case question nor the reason for the topic are discussed much.

\section{Characteristic Actions Level: The Approach}

The case gets discussed in terms of the case provider's actions in this specific situation. What is my working style and why did I choose it? Why did I go for this approach? What are the characteristics of my work style? How do I typically approach assignments? The case provider comes first here. The exploration of deep-seated beliefs is less prevalent at this level.

\section{Views Level: Hidden Drivers}

The case gets discussed in terms of the provider's professional and personal views. What views underlie the diagnosis? How can I explain them? What do they mean and what is their effect on my situation in question? What assumptions about the profession, myself and others became clear in the case discussion? When did things become uncomfortable for me? The specific situation is a tool for learning how to recognize our hidden drivers. These drivers form the behaviour that repeats itself in patterns and influences our way of thinking and acting without us noticing.

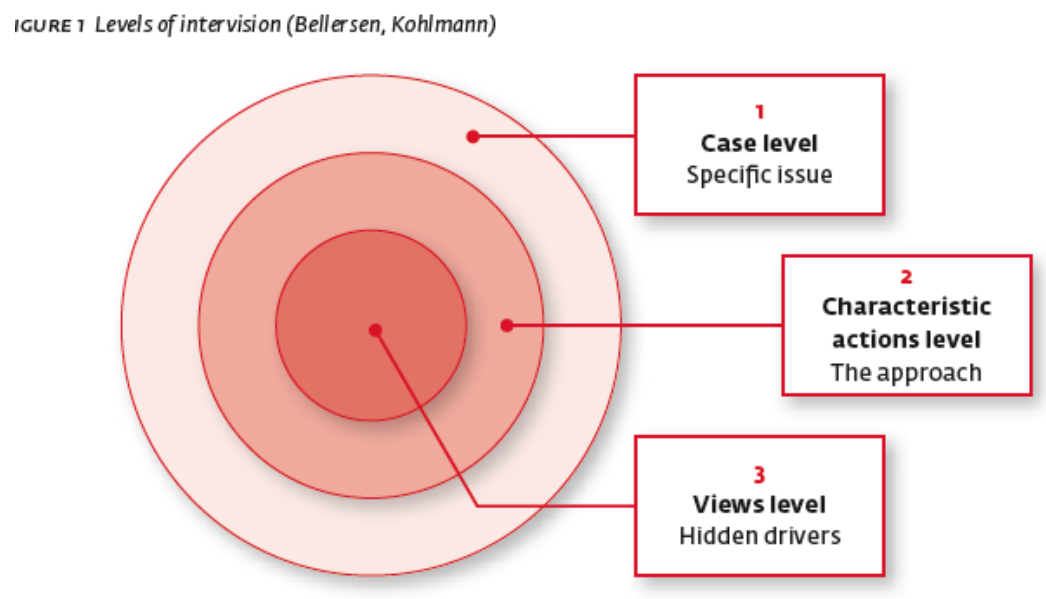

\section{Research Framework}

Participants endorse the value of intervision almost without fail. It seems reasonable therefore, to assume that it leads to the desired professional change. The actual added value of intervision is difficult to describe, however. It is often expressed in terms of results: 'It's proven very useful to me, because it has helped me manage my MT/clients differently'. Or: 'Discussing my case at intervision has given me insights as to why and how to take my next career step.'

There is little research on the added value of intervision for professional practices. All research known to us was conducted in the Netherlands and was primarily focused on peer consultation. However, peer consultation is decidedly different from intervision. 
While peer consultation is mainly a process of testing and assessing, where current actions are compared to the norms and guidelines of others in the professional field, intervision is much more directed at discovering your own professional style and values.

\section{Research Question}

The research at hand focusses on the demand for evidence-based claims of both the effect and added value of intervision. This is linked to the professional practice of management consultants. The research question is as follows:

What is the added value of intervision for management consultants in their professional practice?

\section{Hypotheses}

The following hypotheses are examined:

- Hypothesis 1. The profounder the learning through intervision process, the more the professional experiences added value and intended change.

The basic principle of this hypothesis is that the benefits of intervision are bigger for the participant when beliefs, norms, and values playing a role in the case are dealt with during the intervision (see level three above).

- Hypothesis 2. There is no added value to the professional practice without defining new insights and/or a new approach and experimenting with these.

The basic principle of this hypothesis is that just gaining new insights does not suffice to bring about change or to improve; translating these insights into practical behaviour and actions and experiencing new behaviour is key.

- Hypothesis 3. For intervision to be effective and successful, it is important that the meetings are prepared and organised according to a set of preconditions i.e., the use of a facilitator and an intervision method, a group contract, mutual trust and safety, and integration of reflection in the process.

The basic principle of this is that intervision is methodical, following a certain structure and certain rules. The more methodical the intervision, the bigger the rewards.

\section{Research Method}

The chosen research method is that of qualitative research, because:

1. The research population is small.

2. The interviewees' qualitative experience forms the input, for which (in part) open questions are used. Based on what the responses have in common a demonstrable joint meaning is distilled. 
3. The aim is to develop new contributions to the effectivity of intervision.

4. The research is considered a steppingstone to possible further research.

\section{Research Group}

The research is carried out among Dutch consultants who are members of the Ooa ${ }^{3}$. They actively participated in intervision meetings organised by the Ooa in 2018 .

From this group of about 200 members, $20(10 \%)$ participants were selected randomly.

\section{Characteristics of the Research Group}

- Nearly all interviewees are certified management consultants (Certified Management Consultant)

- The gender distribution is 8 men and 12 women.

- The division of the interviewees' roles in the research is as follows: sixteen participants and four facilitators (intervision moderators) from intervision groups.

- The number of years the interviewees have participated in an intervision group varies:

- $40 \%$ have participated for less than 5 years;

- $20 \%$ have participated between 5 to 10 years;

- $40 \%$ have participated for more than 10 years; $10 \%$ of which have participated for more than 15 years.

- Of all participants $10 \%$ have been a member of the same intervision group for more than a year.

- The number of annual intervision meetings has the following variation:

- $50 \%$ of the interviewees meet 5-6 times a year

- $50 \%$ of the interviewees meet 8 times a year.

- Some groups discuss several cases per meeting.

\section{List of Questions}

The research consists of structured interviews with open questions. To this end, the above research question and hypotheses are translated into a practical set of open interview questions. We opted for open questions because they yield the most information about the intervision experience.

\section{Data Processing}

The results of the interviews are grouped by hypothesis (see above). Key is the added value for the individual in his professional practice. Based on the results the hypotheses are analysed and adjusted if need be. The development of knowledge is at the heart of the matter. The answers are coded to find sufficient pointers to deduce logical knowledge.

\footnotetext{
${ }^{3}$ The Ooa is an ICM, a Dutch institute of management consultancy and member of the International Council of Management Consulting Institutes.
} 
Step1: Open coding of anything that may be of importance to the research by making a selection from the texts (describing the what and why) and making a summary in catchwords. No connections are made yet.

Step 2: Axial coding - determining whether certain open codes recur and if so, give them a shared label. Consequently, a preliminary theory, a concept may emerge.

Step 3: Selective coding - from all codes only the most important are taken into account. Certain codes fail to recur in the interviews and therefore cannot be used to show demonstrable connections.

\section{Results}

- Hypothesis 1. The profounder the learning through intervision process, the more the professional experiences added value and intended change.

The added value of intervision is the shift to a different perspective and formulation of new conduct.

Reflection is considered one of the elements of intervision that add value. Participants experience intervision as holding up a mirror to their own faces. By viewing their professional case from a different perspective, they create room for new approaches.

Regarding the obtained depth of the intervision in relation to the experience with intervision, two images come to the fore:

- Part of the interviewees have the impression that the more experience a participant has with intervision, the more often level three is reached. This is het level of hidden drivers, where the case provider's values and beliefs are the focal point.

- Another part of the interviewees indicates that despite having ample experience with intervision, level two, the characteristics of the case provider's conduct in this specific case, is usually the maximum level that is attained.

The learning outcome is: conduct change in the professional practice.

According to the interviewees, intervision makes them change their modus operandi in their professional practice. It makes them recognise new possibilities; enhanced awareness propels change. The contribution of intervision to the professional development in the consulting practice is described as creating more awareness of your own conduct. It helps develop a wider repertoire of actions to draw from.

Most interviewees indicate that their clients do not indicate or let on that they notice that intervision is taking place. Those that do find the client is aware of something report that the client notices a proportionally larger number of open questions and that the consultant seems to have a more open and independent attitude. 
To obtain depth, both safety and probing questions are required.

How can depth be obtained? The interviewees explain that they learn most when the intervision questions put to them move or touch them, are probing. Those are not the typical 'asked and answered' type of questions, but rather carefully selected ones. On top of that, the interviewees indicate that this is only effective when there is an atmosphere of trust. Do the participants feel safe enough to examine the issues put to the table? After all, intervision is also about matters you are not (yet) aware of. Expressing personal thoughts and feelings is so much easier in a safe environment.

- Hypothesis 2. There is no added value to the professional practice without defining new insights and/or a new approach and experimenting with these.

Intervision is continuous reflection and learning.

Research indicates that intervision is a vehicle for continuous learning and acquiring new insights, which contributes to applying focus to the job at hand. The interviewees indicate to deliberate more before swinging into action; they experiment with their own behaviour to explore the effects and determine possible adaptations to reach their goals. Some interviewees describe an enlarged vocabulary they can use with their clients.

Reflection continues even when an intervision session has finished. Thus, insights into behaviour and conduct will sink in. Some interviewees benefit from writing down the intervision results in a reflection report.

- Hypothesis 3. For intervision to be successful and effective, it is important that the meetings are prepared and organised according to a set of preconditions.

Using an experienced facilitator leads to more depth in the intervision.

The interviewees indicate that an experienced facilitator has the know-how and experience to moderate intervision sessions and is adept at using intervision methods; he knows how to interchange methods. Experienced facilitators are considered to obtain depth sooner than their inexperienced counterparts.

Intervision groups changing their facilitators often do so with the objective to learn how to moderate. The interviewees do not see this as inconvenient, provided there are clear rules and sufficient support from a more experienced facilitator. When part of the intervision participants is too inexperienced in moderating or applying intervision methods, the interviews state they refrain from switching facilitators.

Using a method contributes to the quality of the intervision.

Regarding this statement there are two opposing views. Part of the interviewees says that using an intervision method adds structure to the meeting, which is more effective 
as a result. The opposing view is that the use of an intervision method impedes the sense of freedom; having to follow the steps of a method when discussing a case is experienced as somewhat forced. These interviewees claim that observing those steps too strictly leads to less attention for the case provider.

Interviewees indicate that a method is decided upon in the facilitator/case provider consultation prior to the intervision session. They feel that the method should fit both the case and the case provider. In general, it is the case provider who decides which method he wants to use.

It appears that the method of choice is stuck to; the steps are followed as the method dictates. Sometimes, when a method threatens to deadlock, part of another method is added to get the process going again, e.g. the Gossip method. Whether this happens depends on the case provider's wishes.

\section{The intervision group agrees to a group contract.}

The interviewees share their expectations about intervision. They deem it very important that the dates of the intervision meetings are set and that participants commit to being present at the intervision meetings. When participants do not keep the appointments, they are reminded of their responsibilities during an intervision meeting. Furthermore, the participants enter into an agreement regarding certain elements of the intervision, such as its objectives, who provides a case at which date, and how to refrain from giving advice.

\section{Mutual trust and safety: a tacit pact.}

This research addressed the way safety and mutual trust are safeguarded. It is indicated that this is more of an implicit agreement that is only sometimes made explicit. If safety and trust do come up during a session, it is often the case provider who starts that discussion. However, if people feel comfortable, these subjects remain implicit.

\section{Reflection on intervision.}

The research shows that the ways reflection is dealt with differ between the various intervision groups. According to this research the following forms of reflection were said to be applied:

- At the end of the intervision meeting the intervision groups reflect on what both the case provider and participants have learned.

- Some interviewees stated that the case provider writes a reflection report before the next meeting.

- During the next meeting this case provider is asked what the insights were, which actions he has taken and what their consequences were. 


\section{Conclusions}

The research question is: What is the added value of intervision for management consultants in their professional practice?

The interviewees in this research indicated that to them the added value of intervision is in self-reflection. Intervision serves as a mirror through which they, assisted by others, view their own professional behaviour differently and more consciously and as a result, the interviewees adapt their approach in their professional practice accordingly.

Through experimenting with their own behaviour, interviewees can make adaptations to achieve their goals, thus contributing to their successful professional practice. Reflection usually persists, even after the intervision meeting, allowing insights and approaches to take root. There is a connection between the depth of learning and the added value that is experienced. If level three, the Views level with its 'hidden drivers', is reached, learning will be more profound, providing more insights that touch upon a case provider's values and beliefs.

Of the interviewees, $60 \%$ have been practicing intervision for five years or more. There is no directly demonstrable correlation between experience with intervision and the speed at which level three is reached, and by extension the depth of the results obtained. Depth is primarily the result of a sense of safety and intimacy as well as probing questions. In that process the intervision group members play an important role for the case provider, since they ask the questions that guide him to different perspectives on the issue. Without these questions there is less depth.

The intervision meetings gain value if the following preconditions are met.

- A certain depth in the intervision is obtained sooner with the help of an experienced facilitator.

Trust and safety within the intervision group are important and even essential to reach level three. During the intervision the subjects trust and safety are not explicitly discussed in the interviewees' groups.

- The use of an intervision method gives the meeting structure because its required steps are followed. Interviewees do feel that the use of a method can seem artificial, with perhaps less attention to the case provider as a result.

- The presence of all participants is seen as a precondition for a sound intervision meeting. The groups reach a certain understanding about the participants' presence and expectations in advance. Participants remind each other of their commitments, should this need arise.

Interviewees reflect on intervision in three ways:

- At the end of the intervision meeting the participants evaluate the output.

- In some groups the case provider writes a reflection report.

- During the next intervision meeting, last meeting's case is reflected upon. 
Reflection contributes to the perceived quality of the intervision.

\section{Recommendations}

For management consultants the added value of intervision is a form of reflection that offers the opportunity to gain new insights and for continuous learning. The following recommendations are focussed on achieving added value of intervision as part of the consultants' professional practice.

- To achieve depth mutual trust and a sense of safety in the group is essential. It is a prerequisite to showing their vulnerable sides for both case provider and participants. Precisely because it is so important, the prerequisite should be discussed regularly and explicitly during intervision meetings, to check whether it is still sufficiently met and in what way it can be fostered.

- Operating at level three is to be preferred, because it yields more insights for both the case provider and the participants. Level three is achieved by asking probing questions about the case provider's underlying beliefs, norms and values. By answering these, the beliefs and ideas become more apparent, which enables the case provider to hold them up to the light. How do I observe? How am I controlled by my beliefs? How does that resonate in the current case? This adds depth to the thinking process and enables the formulation of changes as well as their incorporation in the repertoire of actions.

- Learning how to ask and asking probing questions that encourage the case provider's thinking stimulates the intervision atmosphere. It is far from easy to ask questions that genuinely help someone along, because it is difficult to refrain from letting your own images and thoughts about the issue control your questions. Allowing your own views to interfere with the questions impedes mutual trust and openness in intervision.

Questions should be open, without insinuating anything, and should give the case provider room for thought. The group should therefore allow for enough time and attention to getting acquainted with and applying these types of questions.

- Intervision that takes place according to a method gives structure and footing and contributes to the depth of the meeting. It is therefore recommended to use an intervision method and follow the steps involved.

Should the participants experience the method as too artificial, with less attention for the case provider as a result, it is up to the group to check this. The case provider is the only one who can answer that question. The facilitator should first ask the case provider how they experience the method. Should they experience it as too forced as well, the group as a whole can look into ways to loosen things up. 
- To reach quality and depth in intervision, it is advisable to make use of an experienced facilitator. An experienced facilitator is an expert in the intervision process. He uses a range of methods, has experience in group dynamics and controls the quality of the meeting.

\section{Recommendations for Further Research}

Further research could focus on any of the following three areas:

a. What factors contribute to a sense of safety and mutual trust during intervision?

b. Which dynamics can be distinguished in a group and how can those be dealt with most effectively?

c. What are tangible yields of intervision? 


\section{References}

\section{Literature}

Argyris, C., D. Schön, Organizational Learning: A theory of action perspective,AddisonWesley, 1978.

Bateson, G. (1972), Steps to an ecology of mind, New York: Balltanine Books

Bellersen, M. and Kohlmann, I. (2016) Intervision; dialogue methods in action learning, the Netherlands: Vakmedianet

Bellersen, M. and Kohlmann, I (2016) 75 Helpful Questions Game, the Netherlands: Vakmedianet

Dilts, R.B., G. Bonissone, Skills for the future, managing creativity and innovation, Meta Publications, Cupertino, 1993.

Jaworski, J., Synchronicity; the inner path of leadership, Berrett-Koehler, 1996.

Scharmer, C.O., Theory U: learning from the future as it emerges, Berrett-Koehler Publishers, 2007.

Schön, D., The Reflective Practitioner, how professionals think in action, Basic Books, 1983.

Senge, P., O. Scharmer, J. Jaworski, B. Flowers, Presence: exploring profound change in people, organizations and society, Nicholas Brealey Publishing, London, 2004.

\section{A word of thanks}

I would like to thank Wilgard van Lee for his contributions to this research. 